\title{
KAJIAN PUPUK KANDANG TERHADAP INTENSITAS PENYAKIT BERCAK COKLAT SEMPIT (Cercospora oryzae) PADA TANAMAN PADI KETAN PUTIH (Oryzae sativa L. Glutinosa)
}

\author{
Rachmayani Ayu Wira Atmaja *, Sartono Joko Santosa, Siswadi \\ Fakultas Pertanian, Universitas Slamet Riyadi, Surakarta \\ *E-mail: rachmayaniayu98@gmail.com
}

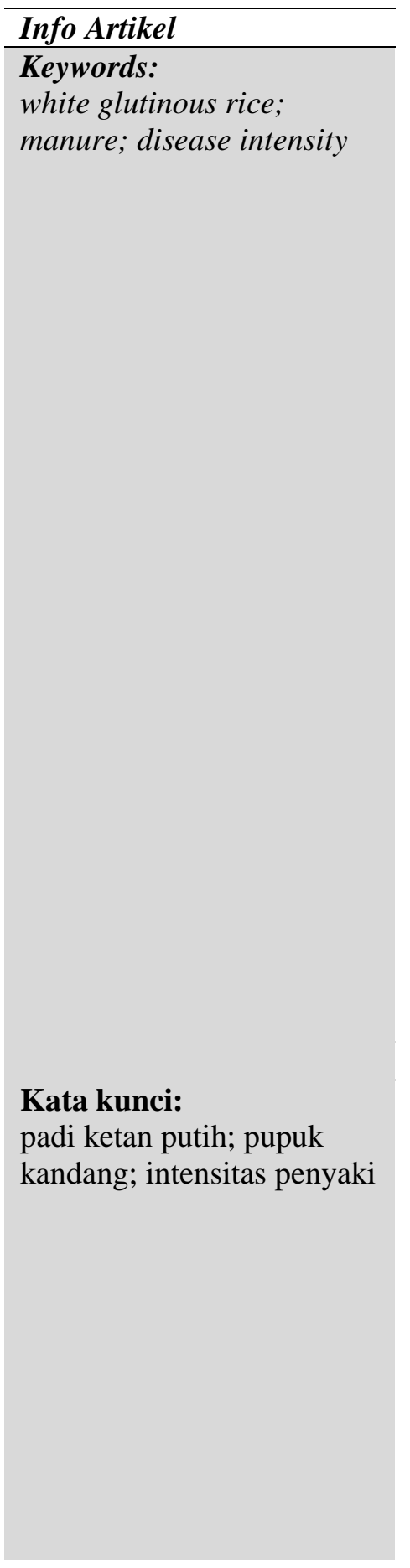

\begin{abstract}
This research entitled Study of Manure on the intensity of Narrow Brown Spot (Cercospora oryzae) on White Glutinous Rice Plants(Oryza sativa L. Glutinosa) with the aim to examine the effect of manure on the intensity of narrow brown spots (Cercospora Oryzae) on white glutinous rice plants. Have been done from 29 October 2019 to 3 March 2020, in the Village of Donohudan, Ngemplak District, Boyolali Regency, Central Java, with an altitude of 150 (masl). This research usedthe method a Randomized Complete Block Design (RCBD) with a single factor consisting of 10 kinds of treatments and repeated 3 times. The combination of treatments as follows: D0, A1, A2, A3, K1, K2, K3, $S 1, S 2, S 3$. The data of this research were analyzed with the HSD test (Honestly Significant Difference) at 5\% significance level, while the results of the research showed that symptom of attacks narrow brown spot (Cercospora oryzae) first appear at the age of 30 days after planting in thr treatment of cow manure, while narrow brown spot (Cercospora oryzae) evenly distributed at the age of 40 days after planting in the treatment of chicken manure and goat manure. Chicken manure with a dose of 4,5 kg/plot could suppress the intensity of narrow brown spot (Cercospora oryzae) disease on the leaves and narrow brown spot (Cercospora oryzae) on the leaves, and the use chicken manure with a dose of $4,5 \mathrm{~kg} / \mathrm{plot}$ give the highest yield in grain weight per plot is1820,90 grams and significantly affect the control treatment or without the provision of manure (an increase of 38,73\%) but did not significantly affect the treatment of goat manure and cow manure.
\end{abstract}

\begin{tabular}{l}
\hline Abstrak \\
\hline Penelitian ini berjudul Kajian Pupuk Kandang Terhadap Intesitas \\
Penyakit Bercak Coklat Sempit (Cercospora oryzae) Pada \\
Tanaman Padi Ketan Putih (Oryza sativa L. Glutinosa) bertujuan \\
untukmengkaji pengaruh pupuk kandang terhadap intensitas \\
penyakit bercak coklat sempit (Cercospora Oryzae) pada tanaman \\
padi ketan putih. Yang dilaksanakan mulai tanggal 29 Oktober \\
2019 sampai 3 Maret 2020, di Desa Donohudan, Kecamatan \\
Ngemplak, Kabupaten Boyolali, Jawa Tengah, dengan ketinggian \\
tempat 150 (mdpl). Penelitian ini menggunakan metode \\
Perancangan Dasar Rancangan Acak Kelompok Lengkap (RAKL) \\
dengan faktor tunggal yang terdiri dari 10 macam perlakuan dan \\
diulang 3 kali. Adapun kombinasi perlakuan sebagai berikut : D0, \\
A1, A2, A3, K1, K2, K3, S1, S2, S3. Data hasil penelitian ini
\end{tabular}




\begin{abstract}
dianalisis dengan uji BNJ (Beda Nyata Jujur) pada taraf nyata 5 $\%$, adapun hasil penelitian menunjukan gejala serangan penyakit bercak coklat sempit (Cercospora oryzae) pertama kali muncul pada umur 30 hari setelah tanam pada perlakuan pupuk pupuk kandang sapi, sedangkan gejala penyakit bercak coklat sempit (Cercospora oryzae) merata pada umur 40 hari setelah tanam pada perlakuan pupuk kandang ayam dan pupuk kandang kambing. Perlakuan pupuk kandang ayam dengan dosis $4,5 \mathrm{~kg} /$ petak dapat menekan intensitas penyakit bercak coklat sempit (Cercospora oryzae) pada daun dan penyakit bercak coklat sempit (Cercospora oryzae) pada batang, serta penggunaan pupuk kandang ayam dengan dosis 4,5 kg/petak memberikan hasil tertinggi pada berat gabah per petak yaitu 1820,90 gram $(8,67$ ton/ha $)$ dan berpengaruh nyata dengan perlakuan kontrol atau tanpa pemberian pupuk kandang (terjadi kenaikan sebesar 38,73\%) tetapi tidak berpengaruh nyata dengan perlakuan pupuk kandang kambing dan pupuk kandang sapi.
\end{abstract}

\title{
PENDAHULUAN
}

Padi ketan adalah bahan pangan yang dapat dimakan sebagai makanan pokok, diolah jadi tepung untuk berbagai macam kue atau makanan kecil. Beras ketan juga bermanfaat untuk kesehatan yang berguna mengatur metebolisme lemak yang normal, sebagai pertumbuhan dan pembentukan tulang juga gigi. Sebagai kesehatan beras ketan dapat mengobati penyakit kencing manis serta diabetes melitus (Santika dan Rozakurniati, 2010). Beras ketan mengandung amilosa yaitu 1-2\% jadi termasuk golongan beras dengan kandungan amilosa rendah $<9 \%$, sedangkan beras biasa mengandung $12-37 \%$ amilosa. Berdasarkan berat kering, beras ketan putih terkandung pati $90 \%$, terdiri amilosa $1-2 \%$ dan amilopektin $88-89 \%$. Dengan demikian amilopektin adalah penyusun terbanyak dalam beras ketan (Priyanto, 2012). Tanaman padi ketan di Indonesia umumnya menghasilkan produksi yang tidak optimal karena berbagai faktor, salah satunya adalah kekurangan unsur hara berupa pemberian bahan organik di dalam tanah sehingga menurunkan produktivitas lahan. Oleh karena itu perlu adanya upaya - upaya dalam menanggulangi masalah tersebut terutama kandungan bahan organik di dalam tanah (Semangun, 2004).

Pemupukan merupakan faktor penting dalam meningkatkan hasil, tetapi usaha petani meningkatkan hasil hanya mengunakan pupuk kimia (anorganik), dalam jumlah yang cenderung meningkat dan kurang memperhatikan kondisi tanah sehingga menimbulkan terjadi ketidakseimbangan unsur hara tanah. Pemakaian pupuk kimia secara terus-menerus dan mengabaikan pemakaian bahan organik untuk mendapatkan hasil optimal menimbulkan kandungan unsur hara tanah turun, kondisi ini menurunkan kesuburan tanah (Rustiarti dan Abdulrachman, 2011). Pemberian pupuk Nitrogen yang tinggi pada awal pertumbuhan akan menyebabkan terbentuknya banyak anakan yang menyebabkan kelembapan lingkungan meningkat, sebaliknya pembentukan anakan padi terhenti bila kandungan $\mathrm{N}$ daun sebesar $2 \%$. Tetapi perlu dipertimbangkan bahwa dengan adanya introduksi varietas berpotensi hasil tinggi, respon terhadap pupuk nitrogen, dapat menyebabkan terjadinya peningkatan perkembangan penyakit tertentu seperti bercak coklat sempit (Mew, 2004).

Penyakit adalah salah satu kendala biotik yang menyebabkan tidak tercapainya potensi hasil. Penyakit bercak coklat sempit Cercospora sering disebut juga sebagai penyakit bercak daun sempit. Penyakit bercak coklat sempit Cercospora menyebekan kerugian sebesar 10\%. Kerugian diakibatkan serangan cendawan Cercospora oryzae Miyake yang menimbulkan proses asimilasi terganggu, pembungaan lambat juga pembentukan biji sehingga menyebabkan hasil rendah (Semangun, 2004). Penelitian bertujuan mengkaji pengaruh pupuk kandang terhadap intensitas penyakit bercak coklat sempit (Cercospora Oryzae) pada tanaman padi ketan putih. Diduga pemberian pupuk kandang ayam 
dengan dosis 3,0 kg/petak dapat menekan intensitas penyakit bercak coklat sempit (Cercospora Oryzae) sehingga dapat memberikan hasil optimal pada tanaman padi ketan putih.

\section{BAHAN DAN METODE}

Penelitian dilaksanakan bulan Oktober 2019 sampai bulan Maret 2020, yang terletak diDesa Donohudan, Kec. Ngemplak, Kab. Boyolali, ketinggian tempat $\pm 150 \mathrm{mdpl}$, jenis tanah grumusol. Bahan yang digunakan yaitu biji padi ketan putih, pupuk Urea, pupuk SP-36, pupuk KCL, pupuk kandang ayam, pupuk kandang kambing, pupuk kandang sapi, air dan tanah/lahan. Sedangkan alat-alat yang digunakan yaitu cangkul, traktor, sabit, gunting, mesin perontok padi, ajir bambu, meteran, rafia, plastik, ember, timbangan, alat tulis dan kertas label.

Penelitian menggunakan Rancangan Acak Kelompok Lengkap (RAKL) dengan faktor tunggal yang terdiri sepuluh macam perlakuan dan diulang tiga kali sehingga diperoleh 30 unit percobaan. Pengamatan dilakukan sejak tanaman berumur 40 hari setelah tanam dengan interval setiap 15 hari sekali. Dengan parameter pengamatan yaitu sebagai berikut :

a) Gejala Serangan Penyakit

Gejala serangan penyakit bercak coklat sempit (Cercospora Oryzae) diamati dengan cara pengamatan secara langsung gejala serangan yang timbul pada daun tanaman yang terserang dengan mengambil gambar. Gejala serangan pertama kali muncul umur 30 HST.

b) Morfologi Patogen

Morfologi patogen diamati dengan cara mengamati secara langsung pada bagian tanaman yang terserang dengan mengambil beberapa sampel pada tanaman yang terserang dan diamati menggunakan mikroskop. Pengamatan ini dilakukan pada saat tanaman berumur 65 HST.

c) Intensitas Serangan Penyakit

Intensitas serangan penyakit bercak coklat sempit (Cercospora oryzae) dapat dihitung dengan rumus :

$I=\frac{\sum(\mathrm{nxv})}{\mathrm{z} \times \mathrm{N}} \mathrm{x} 100 \%$

Keterangan :

I : Intensitas serangan penyakit

$\mathrm{n}$ : Jumlah daun yang terserang

$\mathrm{v}$ : Nilai skala setiap kategori serangan

$\mathrm{N}$ : Jumlah daun yang diamati

$\mathrm{Z}$ : Nilai skala tertinggi

Klasifikasi tingkat kerusakan sebagai berikut :

\begin{tabular}{|c|c|c|c|}
\hline Skala & $\begin{array}{c}\text { Kategori Serangan } \\
\text { (Bercak/Daun) }\end{array}$ & $\begin{array}{c}\text { Persentase Kerusakan Pada } \\
\text { Tanaman }\end{array}$ & Keterangan \\
\hline 0 & Tidak ada bercak & Tidak ada gejala serangan & Sehat \\
\hline 1 & $1-25$ bercak & Kerusakan antara 1\%-25\% & Ringan \\
\hline 2 & $26-50$ bercak & Kerusakan antara $26 \%-50 \%$ & Berat \\
\hline 3 & $51-75$ bercak & Kerusakan antara $51 \%-75 \%$ & Sangat berat \\
\hline 4 & $>75$ bercak & Kerusakan $>75 \%$ & . \\
\hline
\end{tabular}

Intensitas serangan penyakit diamati pada saat tanaman berumur 40 HST hingga tanaman berumur 85 HST, dan diamati setiap 15 hari sekali.

d) Jumlah Anakan per Rumpun

Jumlah anakan per rumpun diamati dengan menghitung anakan secara langsung pada setiap rumpun tanaman. Apabila setiap rumpun tumbuhan padi ketan ada 20 batang, maka jumlah anakan tumbuhan padi adalah 19 batang, karena satu batang sisanya merupakan tanaman padi induk. Pengamatan ini dilakukan sekali pada saat panen.

e) Berat Gabah Per Rumpun (gr)

Berat gabah per rumpun diamati dengan cara menimbang secara langsung seluruh gabah pada setiap rumpun tanaman, dan dilakukan pada saat panen. 
ISSN (Print) : 1693-0738

ISSN (Online) : 2714-5549

Innofarm:Jurnal Inovasi Pertanian Vol. 22 (1), April 2020

f) Berat Gabah per Petak (gr)

Berat gabah per petak diamati dengan menimbang seluruh gabah pada tiap petak tanaman, dan dilakukan pada saat panen.

g) Berat 1000 Gabah (gr)

Berat 1000 Gabah diamati dengan cara menghitung 1000 biji padi pada setiap petak tanaman, kemudian ditimbang 1000 gabah tersebut pada setiap petakan dan dilakukan pada saat panen.

\section{HASIL DAN PEMBAHASAN}

\section{Penyakit Bercak Coklat Sempit Cercospora oryzae}

Hasil pengamatan yang telah dilakukan pada umur 40 hari setelah tanam, telah ditemukan adanya serangan penyakit bercak coklat sempitCercospora oryzae hampir di seluruh pertanaman.

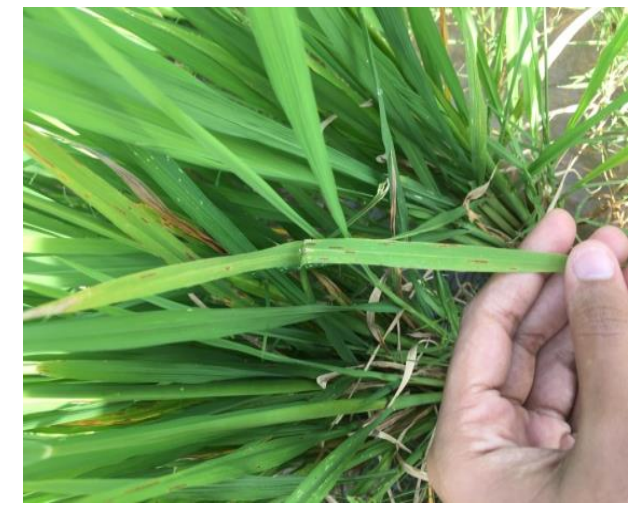

Gambar 1. Gejala penyakit bercak coklat sempit Cercospora oryzae pada daun

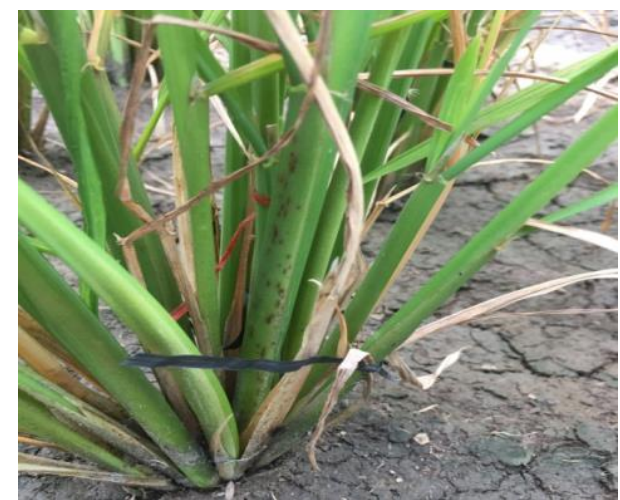

Gambar 2. Gejala penyakit bercak coklat sempit Cercospora oryzae pada batang

Gejala penyakit bercak coklat sempit pertama kali muncul pada umur 30 HST, mengakibatkan telatnya gejala di lapangan, walaupun penyakit bisa menginfeksi pada daun bagian atas atau daun bagian bawah. Berdasarkan sifat biologi dan ekologi jamur, gejala yang ditimbulkan akibat serangan Cercospora oryzae yaitu bercak kecil memanjang seperti garis pendek berrupa coklat merah yang dikelilingi oleh warna kekuningan sejajar tulang daun pada permukaan atas daun, berukuran panjang $\pm 5 \mathrm{~mm}$, lebar 1- 1,5 mm. Hal ini menyebabkan tumbuhan mengering sebelum umurnya serta mengeringnya pelepah yang menimbulkan tanaman padi rebah (Braun, 2000).

\section{Intensitas Penyakit Bercak Coklat Sempit Cercospora oryzae}

Tabel 1. Intensitas penyakit bercak coklat sempit Cercospora oryzae pada daun umur 70 HST

\begin{tabular}{lcccc}
\hline \multirow{2}{*}{ Perlakuan } & \multicolumn{5}{c}{ Purata intensitas penyakit bercak coklat sempit } \\
\cline { 2 - 6 } DO & $21,99 \mathrm{~b}$ & $42,85 \mathrm{bc}$ & $47,89 \mathrm{ab}$ & $77,10 \mathrm{bcd}$ \\
A1 & $20,88 \mathrm{~b}$ & $46,44 \mathrm{c}$ & $46,92 \mathrm{ab}$ & $78,92 \mathrm{bcd}$ \\
A2 & $15,69 \mathrm{ab}$ & $36,96 \mathrm{abc}$ & $38,12 \mathrm{ab}$ & $74,34 \mathrm{ab}$ \\
A3 & $8,64 \mathrm{a}$ & $31,12 \mathrm{a}$ & $34,53 \mathrm{a}$ & $71,43 \mathrm{a}$ \\
K1 & $17,80 \mathrm{~b}$ & $32,80 \mathrm{ab}$ & $43,67 \mathrm{ab}$ & $77,48 \mathrm{bcd}$ \\
K2 & $21,52 \mathrm{~b}$ & $44,28 \mathrm{c}$ & $45,00 \mathrm{ab}$ & $80,63 \mathrm{~cd}$ \\
K3 & $21,70 \mathrm{~b}$ & $43,67 \mathrm{bc}$ & $45,12 \mathrm{ab}$ & $76,56 \mathrm{bc}$ \\
S1 & $20,98 \mathrm{~b}$ & $40,78 \mathrm{abc}$ & $41,99 \mathrm{ab}$ & $78,86 \mathrm{bcd}$ \\
S2 & $22,05 \mathrm{~b}$ & $42,01 \mathrm{abc}$ & $49,31 \mathrm{~b}$ & $81,44 \mathrm{~d}$ \\
S3 & $20,15 \mathrm{~b}$ & $41,64 \mathrm{abc}$ & $43,42 \mathrm{ab}$ & $77,24 \mathrm{bcd}$ \\
\hline Kendanyyyy
\end{tabular}

Keterangan : Angka yang diikuti huruf sama pada kolom berarti tidak berbeda nyata pada taraf $5 \%$ uji BNJ 
Uji BNJ pada pengamatan IV perlakuan pukan ayam dosis 4,5 kg/petak (A3) dapat menekan intensitas penyakit bercak coklat sempit (Cercospora oryzae) dengan purata 71,43 tetapi berbeda tidak nyata dibandingkan perlakuan pukan ayam dengan dosis 3,0 kg/petak (A2) purata 74,34, dan berbeda nyata jika dibandingkan perlakuan pupuk kandang sapi dosis 3,0 kg/petak (S2) dengan purata 81,44.

Pendapat Semangun (2004), mengatakan penyakit ini sangat dipengaruhi kandungan zat hara yang utama $\mathrm{K}$ berpengaruh pada perkembangan penyakit. Tumbuhan padi yang kurang zat $\mathrm{K}$ sangat rentan penyakit bercak coklat sempit $C$. oryzae. Penggunaan pupuk kandang yang mengandung unsur kalium tinggi sangat efektif dalam menekan perkembangan penyakit bercak coklat sempit (Cercospora oryzae). Kandungan kalium pupuk kandang ayam paling besar dibanding pukan kambing dan pukan sapi, sehingga pada pukan ayam dapat menekan serangan bercak coklat sempit $C$. oryzae.

Tabel 2. Intensitas penyakit bercak coklat sempit Cercospora oryzae pada batang umur 85 HST

\begin{tabular}{lcc}
\hline & \multicolumn{2}{c}{ Purata intensitas penyakit bercak coklat sempit } \\
\cline { 2 - 3 } DO & Pengamatan I & Pengamatan II \\
A1 & $26,61 \mathrm{ab}$ & $33,34 \mathrm{abc}$ \\
A2 & $30,68 \mathrm{bcd}$ & $33,34 \mathrm{abc}$ \\
A3 & $32,68 \mathrm{~cd}$ & $33,97 \mathrm{bc}$ \\
K1 & $22,72 \mathrm{a}$ & $31,09 \mathrm{a}$ \\
K2 & $27,30 \mathrm{abc}$ & $32,85 \mathrm{ab}$ \\
K3 & $28,88 \mathrm{bcd}$ & $33,34 \mathrm{abc}$ \\
S1 & $29,67 \mathrm{bcd}$ & $32,29 \mathrm{ab}$ \\
S2 & $30,53 \mathrm{bcd}$ & $34,25 \mathrm{bc}$ \\
S3 & $34,11 \mathrm{~d}$ & $35,64 \mathrm{c}$ \\
\hline
\end{tabular}

Keterangan : Angka yang diikuti huruf sama pada kolom berarti tidak berbeda nyata pada taraf 5\% uji BNJ

Uji BNJ pada pengamatan II perlakuan pukan ayam dosis 4,5 kg/petak (A3) dapat menekan intensitas penyakit bercak coklat sempit (Cercospora oryzae) dengan purata 31,09 namun tidak berbeda nyata dibanding perlakuan tidak menggunakan pukan (D0) dengan purata 33,34, perlakuan pukan ayam dosis $1,5 \mathrm{~kg} /$ petak (A1) purata 33,34 , perlakuan pukan kambing dosis $0,45 \mathrm{~kg} /$ petak (K1) purata 32,85 , perlakuan pukan kambing dosis $0,90 \mathrm{~kg} /$ petak (K2) purata 33,34, perlakuan pukan kambing dosis 1,35 kg/petak (K3) purata 32,29 serta berbeda nyata perlakuan pukan sapi dosis 3,0 $\mathrm{kg} /$ petak purata 34,25 .

Penyakit bercak coklat sempit terjadi karna faktor biotik dan abiotik sesuai perkembangan jamur pada siklus penyakit tanaman yaitu inokulasi, sporulasi, dan penyebarannya. Penyakit terjadi jika varietas tumbuhan ditanam diareal lahan yang mudah terinfeksi jamur Cercospora oryzae contohnya pertanaman yang banyak memakai pupuk unsur $\mathrm{N}$, karna faktor kekuatan varietas, cuaca, ada luka serta populasi vektor penyebar penyakit tinggi (Ginting, 2008).

Selain dari perlakuan, faktor sekitar juga berpengaruh pada perkembangan tumbuhan padi rentan serta menciptakan keadaan yang sama untuk hidupnya jenis jamur penyebab penyakit bercak coklat sempit. Faktor pendukung oleh iklim mikro (curah hujan, lahan, air, sinar matahari dan zat hara) serta tumbuhan inang yang tidak tahan menimbulkan pertumbuhan jamur menginfeksi tumbuhan padi saat fase vegetative, ditandai ada gejala penyakit bercak coklat sempit (Adinugroho, 2008). 
ISSN (Print) : 1693-0738

ISSN (Online) : 2714-5549

Innofarm:Jurnal Inovasi Pertanian Vol. 22 (1), April 2020

HASIL TANAMAN

Tabel 3. Hasil tanaman padi

\begin{tabular}{|c|c|c|c|c|}
\hline \multirow[b]{2}{*}{ Perlakuan } & \multicolumn{4}{|c|}{ Pengamatan Hasil Padi Ketan Putih } \\
\hline & $\begin{array}{c}\text { Jumlah Anakan per } \\
\text { Rumpun }\end{array}$ & $\begin{array}{l}\text { Berat Gabah per } \\
\text { Rumpun (gr) }\end{array}$ & $\begin{array}{l}\text { Berat Gabah per } \\
\text { Petak (gr) }\end{array}$ & $\begin{array}{c}\text { Berat } 1000 \text { Gabah } \\
\text { (gr) }\end{array}$ \\
\hline D0 & $22,625 \mathrm{ab}$ & 39,86 a & 1115,58 a & 31,40 a \\
\hline A1 & $26,542 \mathrm{abc}$ & 54,69 a & $1420,87 \mathrm{ab}$ & $36,57 \mathrm{ab}$ \\
\hline A2 & $30,458 \mathrm{bc}$ & 49,56 a & $1536,50 \mathrm{ab}$ & $36,67 \mathrm{ab}$ \\
\hline A3 & $31,833 \mathrm{c}$ & 48,03 a & $1820,90 \mathrm{~b}$ & $34,60 \mathrm{ab}$ \\
\hline K1 & 19,042 a & 44,09 a & $1356,08 \mathrm{ab}$ & $36,57 \mathrm{ab}$ \\
\hline $\mathrm{K} 2$ & 21,583 a & $46,57 \mathrm{a}$ & $1372,54 \mathrm{ab}$ & $36,53 \mathrm{ab}$ \\
\hline K3 & $21,625 \mathrm{a}$ & 49,15 a & $1476,56 \mathrm{ab}$ & $36,87 \mathrm{~b}$ \\
\hline S1 & $20,250 \mathrm{a}$ & 42,33 a & $1328,62 \mathrm{ab}$ & $36,83 \mathrm{~b}$ \\
\hline $\mathrm{S} 2$ & $21,000 \mathrm{a}$ & $45,74 \mathrm{a}$ & $1345,93 \mathrm{ab}$ & $33,73 \mathrm{ab}$ \\
\hline S3 & $22,583 \mathrm{ab}$ & 52,81 a & $1432,44 \mathrm{ab}$ & $35,97 \mathrm{ab}$ \\
\hline
\end{tabular}

Keterangan : Angka yang diikuti huruf sama pada kolom berarti tidak berbeda nyata pada taraf $5 \%$ uji $\mathrm{BNJ}$

Uji BNJ jumlah anakan paling tinggi yaitu perlakuan pukan ayam dosis 4,5 kg/petak (A3) purata 31,83 namun berbeda tidak nyata jika dibandingkan perlakuan pukan ayam dosis 1,5 kg/petak (A1) purata 26,53, perlakuan pukan ayam dosis $3,0 \mathrm{~kg} / \mathrm{petak}$ (A2) purata 30,47, dan berbeda nyata perlakuan pupuk kandang kambing dosis $0,45 \mathrm{~kg} /$ petak (K1) purata 19,17, perlakuan pukan kambing dosis $0,90 \mathrm{~kg} /$ petak $(\mathrm{K} 2)$ purata 21,27, perlakuan pukan kambing dosis 1,35 kg/petak (K3) purata 21,63 , perlakuan pukan sapi dosis $1,5 \mathrm{~kg} /$ petak (S1) purata 20,27, perlakuan pupuk kandang sapi dosis $3,0 \mathrm{~kg} /$ petak (S2) purata 20,83, dan perlakuan pukan sapi dosis 4,5 kg/petak (S3) purata 22,63. Jumlah anakan per rumpun mempengaruhi intensitas penyakit bercak coklat sempit. Berdasarkan hasil analisis menunjukkan bahwa jumlah anakan per rumpun berkolerasi negatif dengan intensitas penyakit bercak coklat sempit. Artinya bahwa semakin banyak jumlah anakan per rumpun maka tingkat intensitas penyakit bercak coklat sempit cenderung menurun. Pertumbuhan jumlah anakan pada perlakuan pukan ayam dosis 4,5 kg/petak (A3) memungkinkan banyak daun yang saling menutupi karena banyaknya jumlah anakan sehingga intensitas cahaya yang diterima lebih rendah dan membuat kelembapan disekitar tanaman meningkat. Besarnya intensitas penyakit bercak coklat sempit secara akumulatif dipengaruhi oleh kandungan $\mathrm{K}$ yang tinggi, sehingga tanaman yang kandungan $\mathrm{K}$ nya tinggi menurunkan intensitas penyakit bercak coklat sempit.

Hasil Uji BNJ menunjukkan bahwa berat gabah perrumpun tertinggi pada pukan ayam dosis 1,5 $\mathrm{kg} /$ petak (A1) dengan purata 54,69 namun tidak berbeda nyata dibandingkan perlakuan tanpa pemberian pukan (D0) purata 39,86, perlakuan pukan ayam dosis 3,0 kg/petak (A2) dengan 49,56, perlakuan pukan ayam dosis 4,5 kg/petak (A3) purata 48,03, perlakuan pukan kambing dosis 0,45 $\mathrm{kg} /$ petak (K1) purata 44,09, perlakuan pukan kambing dosis 0,90 kg/petak (K2) purata 46,57, perlakuan pukan kambing dosis $1,35 \mathrm{~kg} /$ petak (K3) purata 49,15, perlakuan pukan sapi dosis 1,5 $\mathrm{kg} /$ petak (S1) purata 42,33, perlakuan pukan sapi dosis 3,0 kg/petak (S2) purata 45,74, dan perlakuan pukan sapi dosis 4,5 kg/petak (S3) purata 52,81. Di dalam pukan ayam terkandung zat Nitrogen 1,65 $\%$, Pospor $0,94 \%$, serta Kalium 1,12 \%. Diduga unsur P terdapat dalam pupuk kandang ayam mengandung zat hara yang banyak dibandingkan pupuk yang lain, sehingga penyerapan zat hara mencukupi bagi tumbuhan. Demikian halnya dengan pendapat Sigit, W. (2019), yang mengatakan penggunaan pupuk kandang ayam 37,5 gr/tanaman memberikan pengaruh nyata pada pertumbuhan 
bibit sengon dan berat segar bibit sengon. Banyaknya pupuk yang diberikan tergantung jenis tanaman, umur bibit dan jenis media.

Hasil Uji BNJ berat gabah perpetak tertinggi perlakuan pupuk kandang ayam dosis 4,5 kg/petak (A3) purata 1820,90 tetapi berbeda tidak nyata jika dibandingkan perlakuan pupuk kandang ayam dosis 1,5 kg/petak (A1) purata 1420,87, perlakuan pupuk kandang ayam dosis 3,0 kg/petak (A2) purata 1536,50, perlakuan pupuk kandang kambing dosis $0,45 \mathrm{~kg} /$ petak (K1) purata 1356,08, perlakuan pupuk kandang kambing dosis $0,90 \mathrm{~kg} /$ petak (K2) purata 1372,54, perlakuan pupuk kandang kambing dosis $1,35 \mathrm{~kg} /$ petak (K3) purata 1476,55, perlakuan pupuk kandang sapi dosis 1,5 kg/petak (S1) purata 1328,62 , perlakuan pupuk kandang sapi dosis 3,0 kg/petak (S2) purata 1345,93, perlakuan pupuk kandang sapi dosis $4,5 \mathrm{~kg} /$ petak (S3) purata 1432,44 dan berbeda nyata perlakuan tanpa pemberian pupuk kandang (D0) purata 1115,58. Menurut hardjowigeno (1995), unsur N yang ada di dalam pupuk sesudah diserap tumbuhan adalah penyusun BO baik padadaun atau pada biji, jadi pemberian pupuk yang terkandung $\mathrm{N}$ dalam tumbuhan dapat meningkatkam berat gabah. Selain unsur $\mathrm{N}$ pupuk kandang ayam mengandung $\mathrm{P}$ agak tinggi, dimana $\mathrm{P}$ merupakan unsur penting pada pertumbuhan bunga, pengisian gabah serta membuat gabah menjadi bernas, jadi pemberian $\mathrm{P}$ tinggi cukup meningkatkan produksi gabah.

Hasil Uji BNJ menunjukkan bahwa berat 1000 gabah tertinggi pada perlakuan pukan kambing dosis $1,35 \mathrm{~kg} /$ petak (K3) purata 36,87 tetapi tidak berbeda nyata dibandingkan pukan kandang ayam dosis 1,5 kg/petak (A1) purata 36,57, perlakuan pukan ayam dosis 3,0 kg/petak (A2) purata 36,67, perlakuan pukan ayam dosis 4,5 $\mathrm{kg} /$ petak (A3) purata 34,60, perlakuan pukan kambing dosis 0,45 $\mathrm{kg} /$ petak (K1) purata 36,57, perlakuan pukan kambing dosis 0,90 kg/petak (K2) purata 36,53, perlakuan pukan sapi dosis $1,5 \mathrm{~kg} /$ petak (S1) purata 36,83 , perlakuan pukan sapi dosis $3,0 \mathrm{~kg} / \mathrm{petak}$ (S2) purata 33,73, perlakuan pukan sapi dosis 4,5 kg/petak (S3) purata 35,97 dan berbeda nyata perlakuan tanpa pemberian pukan (D0) purata 31,40. Pemberian pukan ayam, kambing dan sapi menghasilkan berat 1000 gabah cukup tinggi daripada tidak menggunakan pupuk kandang. Diduga karna persentaase gabah berkualitas disebabkan karna keadaan lingkungan yaitu jenis dan dosis pupuk Nitrogen, Pospor dan Kalium yang terkandung pada pukan ayam, pukan kambing serta pukan sapi yang telah jadi mampu memperbaiki sifat fisik, kimia dan biologi tanah. Penelitian Rasyad dan Idwar (2010), berat gabah bernas lebih dominan dipengaruhi oleh lingkungan penanaman dibanding faktor genetik tanaman.

\section{KESIMPULAN}

Berdasarkan hasil penelitian dari perlakuan pupuk kandang terhadap intensitas penyakit bercak coklat sempit (Cercospora oryzae), maka dapat disimpulkan sebagai berikut :

1. Gejala serangan penyakit bercak coklat sempit (Cercospora oryzae) pertama kali muncul pada umur 30 hari setelah tanam pada perlakuan pupuk pupuk kandang sapi, sedangkan gejala penyakit bercak coklat sempit (Cercospora oryzae) merata pada umur 40 hari setelah tanam pada perlakuan pupuk kandang ayam dan pupuk kandang kambing.

2. Perlakuan pukan ayam dosis $4,5 \mathrm{~kg} /$ petak berpengaruh nyata dalam menekan intensitas penyakit bercak coklat sempit (Cercospora oryzae) pada daun dan pada batang sedangkan pada perlakuan pupuk kandang sapi dengan dosis 3,0 kg/petak berpengaruh nyata dalam meningkatkan intensitas penyakit bercak coklat sempit (Cercospora oryzae) pada daun dan pada batang tetapi tidak berpengaruh nyata pada perlakuan pupuk kandang kambing terhadap intensitas penyakit bercak coklat sempit (Cercospora oryzae) pada daun dan pada batang.

3. Penggunaan pukan ayam dosis $4,5 \mathrm{~kg} /$ petak memberikan hasil tertinggi pada berat gabah per petak yaitu 1820,90 gram (8,67 ton/ha), dan berpengaruh nyata dengan perlakuan kontrol atau tanpa pupuk pemberian kandang (terjadi kenaikan sebesar 38,73\%) tetapi tidak berpengaruh nyata dengan perlakuan pupuk kandang kambing dan pupuk kandang sapi.

\section{DAFTAR PUSTAKA}


Adinugroho, W. C. 2008. Konsep Timbulnya Penyakit Tanaman. IPB : Mayor Silvicultura Tropika Pasca Sarjana IPB.

Ginting, M. S. 2008. Intensitas Serangan Penyakit Bercak Coklat Sempit (Cercospora oryzae) (Rocid) ). Const Pada Beberapa Varietas Padi Sawah (Oryza sativa .L) dengan Jarak Tanam Yang Berbeda di Lapangan. Skripsi. Medan : Fakultas Pertanian Universitas Sumatera Utara.

Hardjowigeno, S. 1995. Ilmu Tanah. Jakarta. Akademi Presindo.

Mew, T. W. 2004. Four decades of fungi blight of rice research. Abstract. The 1 st Internasional Conference on Fungi Blight of Rice. Ministry of Education, Culture, Sports, Science and Technology (MEXT) National Institut of Agrobiological Science (NIAS) and Phytopathological Society of Japan.

Priyanto T. 2012. Beras Ketan \& Sifat Fisika - Kimianya. http://www.alatcetakrengginang.com/2012/02/beras-ketan-sifat-fisika-kimianya.html. 12 Mei 2013.

Rasyad, A. Dan Idwar. 2010. Interaksi Genetik x Lingkungan dan Stabilitas Komponen Hasil Berbagai Genotipe di Provinsi Riau. Jurnal Agronomi Indonesia, volume 38 (1) : 25 - 29.

Rustiarti .T., dan S. Abdulrachman. 2011. Komparatif beberapa metode penetapan kebutuhan pupuk adaptasi varietas dan evaluasi kebutuhan pupuk padi gogo pada tanaman padi. Balai Besar Penelitian Tanaman Padi. Badan penelitian dan Pengembangan Pertanian, Kementerian Pertanian. Hal 1065-1077.

Santika, A., dan Rozakurniati. 2010. Teknik Evaluasi Mutu Beras Hitam dan Beras Merah pada Beberapa Galur Padi Gogo. Buletin Teknik Pertanian Vol. 15 No. 1 Hal. 1-5.

Semangun, H. 2004. Penyakit-Penyakit Tanaman Pangan di Indonesia. Yogyakarta: Universitas Gajah Mada.

Sigit Wijayanto, Dewi Ratna Nurhayati, Efrain Patola. 2019. Kajian Dosis Pupuk Kandang Ayam dan Frekuensi Penyiraman terhadap Pertumbuhan Bibit Sengon (Paraserianthes falcataria $(L)$ Nielson). Innofarm Jurnal Inovasi Pertanian vol 21 (2), Oktober 2019. ISSN (Print) : 16930738 . 